\title{
OPEN Heat insulation effect in solar radiation of polyurethane powder coating nanocomposite
}

\begin{abstract}
Ali Akbar Azemati ${ }^{1,2}$, Seyed Saeid Rahimian Koloor ${ }^{3 凶}$, Hossain Khorasanizadeh ${ }^{1}$, Michal Petrư ${ }^{4}$, Ghanbar Ali Sheikhzadeh ${ }^{1}$, Mahdi Safi ${ }^{5}$ \& Behzad Shirkavand Hadavand ${ }^{6}$

This study aims to improve polyurethane-based coating by modified zirconium oxide and aluminum oxide nanoparticles for preparing thin polymeric heat insulation coatings. In the first step, the nanoparticles were chemically modified with the silane coupling agent. Then, three different weight percent of modified nanoparticles $(1,3$, and $5 \% \mathrm{w} / \mathrm{w})$ were mixed with polyurethane, to prepare the nanocomposites, which were coated on metallic plate samples. Then, these plates are used to measure the radiation heat transfer coefficients, absorption coefficient in a region of short wavelengths (UV/VIS/NIR), the emissivity coefficient, and thermography of the samples in a region of long wavelengths (IR). Results showed that by adding the modified nanoparticles to the polyurethane matrix, absorption was decreased and the emissivity coefficient was increased. According to the thermography results, it was observed that the surface temperature of both samples with $3 \% \mathrm{w} / \mathrm{w}$ of nanoparticles had the minimum temperature compare to others. Minimum heat surface observed for $3 \% \mathrm{w} / \mathrm{w}$ of modified nano zirconium oxide.
\end{abstract}

Energy conservation has gained importance in many advanced industries as a part of eco-efficiency. In this regard, the used of advanced nanocomposites and structural coating has become one of the innovative approach in energy conservation applications ${ }^{1,2}$. Reinforced composites using microfibers and ceramic particles in the form of thin layer and coatings, are effectively used to enhance the mechanical features ${ }^{3,4}$ while reducing the emissivity coefficient and heat transfer that results in reducing the thermal energy and annual electricity consumption ${ }^{5-8}$, while in buildings under different climate changes. The absorption and emission of the coating material features are known to be important in surface heating, which could be controlled to produce a coating with cooling features. The cooling effect is measured by the reflection of the surface solar radiation, as well as the surface emissivity, as reflected back into the atmosphere. Such a concept was used for white materials in construction applications (e.g. roof surface) where is subjected to large solar radiation and has a high reflectance ${ }^{9-12}$.

A testing method has been developed to evaluate the energy performance and sustainability of innovative new products, which are known as cool colors ${ }^{13}$. These products were the component of selective materials (high absorption coefficient in the visible light region and high reflectance in the infrared light region), and consequently, they had both the aesthetics and cooling capabilities parameters in construction application.

Joudi $^{14}$ studied the radiation properties of the surface, including the emissivity coefficient of interior surfaces, modeling methods, and its results on building energy performance and the thermal environment of buildings. This study indicated that surface with low emissivity can increase indoor air temperature vertical gradient, which is dependent on the time of day and outside weather conditions.

In other research by Ascione et al. ${ }^{15}$, a new method was implemented, in which thermo-physical properties of a building and coatings were optimized by changing the thermal resistance, capacity, and radiation properties of the surfaces exposed to radiation. In summer, the majority of cooling load faced on the building as a result of solar radiation is on the external walls of buildings. By reducing the amount of solar radiation absorbed by the external walls, the cooling load can be highly reduced. Although, the facade of the building and constructional

\footnotetext{
${ }^{1}$ Department of Thermo Fluids, Faculty of Mechanical Engineering, University of Kashan, Kashan 8731753153, Iran. 'Department of Mechanical Engineering, Abadan Branch, Islamic Azad University, Abadan 6317836531, Iran. ${ }^{3}$ Institute for Nanomaterials, Advanced Technologies and Innovation (CXI), Technical University of Liberec (TUL), 46001 Liberec, Czech Republic. ${ }^{4} T e c h n i c a l$ University of Liberec (TUL), 46001 Liberec, Czech Republic. ${ }^{5}$ Department of Color Imaging and Color Image Processing, Institute for Color Science and Technology, Tehran 1668836471, Iran. ${ }^{6}$ Department of Resin and Additives, Institute for Color Science and Technology, Tehran 1668836471, Iran. ${ }^{\circledR}$ email: s.s.r.koloor@gmail.com; shirkavand@icrc.ac.ir
} 


\begin{tabular}{|l|l|l|}
\hline Samples & Nano $\mathrm{ZrO}_{2}(\%)$ & Nano $\mathrm{Al}_{2} \mathrm{O}_{3}$ (\%) \\
\hline Blank & 0 & 0 \\
\hline PU-1\% nano $\mathrm{ZrO}_{2}$ & 1 & 0 \\
\hline PU-3\% nano $\mathrm{ZrO}_{2}$ & 3 & 0 \\
\hline PU-5\% nano $\mathrm{ZrO}_{2}$ & 5 & 0 \\
\hline PU-1\% nano $\mathrm{Al}_{2} \mathrm{O}_{3}$ & 0 & 1 \\
\hline PU-3\% nano $\mathrm{Al}_{2} \mathrm{O}_{3}$ & 0 & 3 \\
\hline PU-5\% nano $\mathrm{Al}_{2} \mathrm{O}_{3}$ & 0 & 5 \\
\hline
\end{tabular}

Table 1. Polyurethane power coatings nanocomposite samples.

materials used for the exterior surface is mostly decorative elements, but they play an important role in controlling the absorption of solar radiation ${ }^{16}$.

There reflectance properties of metal oxide nanoparticles in the infrared region (NIR) were studied by Jeevanandam and his co-works ${ }^{17}$. They compared reflectance ability between nanocrystalline metal oxide powder, mineral, and common macrocrystalline in the infrared region (NIR). They showed that nanocrystalline metal oxide in the infrared region (NIR) has $15-20 \%$ higher reflectance, which could be due to the coupled small crystalline particles that are produced from smaller particles according to the Kubelka-Munk theory ${ }^{18}$. Also, a comparison between the reflectance properties of nanocrystalline metal oxides and macrocrystalline in the near-infrared region shows that the nanocrystalline metal oxides have more reflectance ${ }^{17,19}$. Some researchers investigated the effect of zirconium oxide and aluminum oxide nanoparticles in ultraviolet curable coatings ${ }^{20,21}$, and also thermal degradation kinetics of these particles in powder coatings ${ }^{22-24}$. These researches intend to study the ability of nanoparticles added coating to reduce the heat transfer, where uses polyurethanes resin with high durability, resistance to the ultraviolet (UV) irradiation, and good adhesion to metallic surface features ${ }^{25-27}$.

As a thermal barrier, polymer coatings have to be made with specifically large thicknesses as foams or porous composites, which is the main disadvantage of such coating and limit its application. Therefore, to achieve a thin and durable coating with thermal barrier properties, a special material is required. One of the ways is to use suitable additives such as nanoparticles in the coating structure. In recent years, the use of powder coatings to coat metal products that are exposed to direct sunlight, become a common choice to prevent them from the transfer of radiant heat energy of the sun. For example, in the insulation of metal canopies and air conditioners exposed to sunlight, a thin insulating coating with a thermal insulating property is required in addition to creating a suitable appearance. Since the use of powder coatings to cover metal products has become common in recent years, and in some cases, the manufactured products are exposed to direct sunlight, it is necessary to protect the transfer of radiant thermal energy. In this regard, this study focused on the idea of using nanoparticles in powder coatings that are able to reflect sunlight, as one of the solutions to provide the coating with a proper thermal resistance in addition to a suitable low thickness.

\section{Materials and method}

Materials. Vinyltrimethoxysilane (VTMS) and isopropyl alcohol were provided from Merck Co. (Germany) and used for the chemical modification of nanoparticles. Formulated polyurethane powder coating resin 9016 WU18AX was prepared in Peka Chimie Co. (Iran). The nano $\mathrm{ZrO}_{2}$ and $\mathrm{Al}_{2} \mathrm{O}_{3}(40 \mathrm{~nm}$ ) were purchased from US Research Nanomaterials Inc. (USA).

Preparation of polyurethane nanocomposite. Nano $\mathrm{ZrO}_{2}$ and $\mathrm{Al}_{2} \mathrm{O}_{3}$ particles were chemically modified by a silane coupling agent ${ }^{28,29}$. Then, polyurethane resin and different percentages $(1,3$, and $5 \% \mathrm{w} / \mathrm{w})$ of modified nano $\mathrm{ZrO}_{2}$ and $\mathrm{Al}_{2} \mathrm{O}_{3}$ particles were extruded in the twin screw extruder (Yantai Donghui Powder Processing Equipment Company, China). The prepared chips were powdered and sieved to the average particle size of $55 \mu \mathrm{m}$. The nanocomposite was electrostatically coated on $10 \times 15 \mathrm{~cm}^{2}$ galvanized plate and cured at $180{ }^{\circ} \mathrm{C}$ for $15 \mathrm{~min}$. The composition of samples is presented in Table 1.

Instruments and test methods. The hemispherical total reflectance and emissivity were measured by emissometer/ reflectometer AZ-Technology's TEMP 2000A model (USA) in the range of long wavelengths from less than $3 \mu \mathrm{m}$ to greater than $35 \mu \mathrm{m}$ (infrared region) and measurement accuracy (for specular and diffuse samples) $1 \%$ of full scale for gray samples and $3 \%$ of full scale for non-gray samples. Due to the changes in the reflectance and emissivity coefficient, the coating performance is related to the wavelength in all wavelengths and then assumed as the non-gray body. This instrumentation is not limited in wavelength range due to filters, windows, or coatings, placed in the optical path. The measurements were repeated five times at different parts of each sample, according to ASTM E408 test method ${ }^{30}$. In long wavelengths, the absorption and emissivity coefficient for the black body was the same. Also, due to the constant temperature in the experimental test, it is assumed that thermal equilibrium is established and according to Kirchhoff's law ${ }^{31}$, if there is thermal equilibrium in the long wavelengths, absorption and emissivity coefficient can be considered equal for all samples ${ }^{32,33}$.

A large amount of solar heat gain is in the region wavelength between 0.2 and $2.5 \mu \mathrm{m}$ (UV/Vis/NIR) ${ }^{32}$. Similarly, the Shimadzu spectrophotometer UV-3600 model (Japan) was used to obtain the amount of reflection coefficient of the surfaces in the same wavelengths at this region. 


\begin{tabular}{|l|l|l|l|l|l|l|}
\hline \multirow{2}{*}{ Time } & \multicolumn{2}{|l|}{ Air temperature $\left({ }^{\circ} \mathbf{C}\right)$} & $\begin{array}{l}\text { Relative } \\
\text { humidity }(\%)\end{array}$ & $\begin{array}{l}\text { Wind speed } \\
(\mathbf{m} / \mathbf{s})\end{array}$ & $\begin{array}{l}\text { Maximum solar heat } \\
\text { gain }\left(\mathbf{w} / \mathbf{m}^{2}\right)^{\mathbf{a}}\end{array}$ \\
\cline { 2 - 7 } & Daily average & Daily maximum & Daily minimum & 19 & 3.13 & 768 \\
\hline $\begin{array}{l}\text { Sunny summer } \\
\text { day 1:00 PM }\end{array}$ & 32 & 36 & 21 & 19 & \\
\hline
\end{tabular}

Table 2. Environment weather conditions in the time of experiments. ${ }^{a}$ Obtained by Carrier software.

The wavelength accuracy in ultraviolet and visible regions is $\pm 0.2 \mathrm{~nm}$, in near-infrared region is $\pm 0.8 \mathrm{~nm}$, for wavelength repeat accuracy ultraviolet and visible regions is within $\pm 0.08 \mathrm{~nm}$ and for the near-infrared region is within $\pm 0.32 \mathrm{~nm}$.

A $50 \mathrm{~W}$ halogen lamp and deuterium lamp (socket type) have a built-in mechanism for automatically adjusting the light-source position. The measurements were performed in the range of 282 to $393 \mathrm{~nm}$ at least five times at different parts of each sample according to ASTM E903-96 test method $^{34}$.

Infrared thermography (IRT) was measured in 8-15 $\mu \mathrm{m}$ (infrared region) with infrared camera Testo, 875-2 model (Germany). According to the obtained results and given that the transmission coefficient is zero $(\tau=0)$, the absorption coefficient can be calculated using Eq. $(1)^{33}$ :

$$
\alpha+\tau+\rho=1
$$

where $\alpha$ is absorption coefficient, $\tau$ is transmission coefficient and $\rho$ is reflection coefficient.

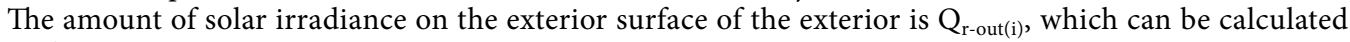
using the equation:

$$
Q_{r-o u t(i)}=\alpha q_{s}-\varepsilon \sigma\left(T_{s}^{4}-T_{s k y}^{4}\right)
$$

where $\varepsilon$ is the emissivity coefficient, $\mathrm{T}_{\mathrm{s}}$ is the surface temperature, $\mathrm{q}_{\mathrm{s}}$ is solar incident radiation and $\mathrm{T}_{\text {sky }}$ is the sky temperature.

According to Eq. (2), if the emissivity coefficient is high, the amount of incident solar radiation heat flux to the exterior surfaces is reduced. This decreases the temperature of the interior surface, and therefore reduces the amount of cooling load necessary to bring the temperature of the interior space to the comfort temperature zone.

The amount of light passing through the atmosphere is not the same for all wavelengths and only in certain areas light passing is high and unlimited. Therefore, the amount of irradiance in the regions of $0.4-1.5,1.5-2.5$, $3-5$, and 8-12 $\mu \mathrm{m}$ could be extraordinary and could be used for electro-optical systems. Meanwhile, only the regions of 3-5 and 8-12 $\mu \mathrm{m}$ are appropriate to make and apply passive infrared imaging system (i.e. thermography). Since, objects have significant reflectance in ambient temperature conditions, only in these two regions (3-5 and $8-12 \mu \mathrm{m})$ and are not absorbed by atmospheric effects.

The thermography measurement was performed outdoors and exposed to direct sunlight at noon on a sunny summer day. The samples were on a plastic platform to eliminate the effects of heat transfer between platform and samples. Data of weather conditions including temperature, relative humidity, wind speed, and amount of solar radiation are obtained from the local weather center as presented in Table 2.

\section{Results and discussion}

Morphology. The scanning electron microscope (SEM) images of polyurethane nanocomposite with different amounts of modified nano $\mathrm{ZrO}_{2}$ and $\mathrm{Al}_{2} \mathrm{O}_{3}$ particles are shown in Fig. 1. In general, a good dispersion of nanoparticles in the urethane matrix could be viewed in samples with modified nano $\mathrm{ZrO}_{2}$, which is the effect of modification on the dispersion of nanoparticles. The best dispersion with the suitable percentage of nanoparticles was observed in a sample with $3 \% \mathrm{w} / \mathrm{w}$ nano $\mathrm{ZrO}_{2}$ Increasing the nanoparticles to $5 \% \mathrm{w} / \mathrm{w}$ results in the adhesion and aggregation of the particles. It's well known that property and response of composites depends to the amount and disperse state of nano reinforcement materials $s^{3,35,36}$. The addition of nanomaterial in a certain amount could improve the properties, while the excessive addition could result in the agglomeration that causes a drop in the properties. The SEM images indicate that the reason for better absorption and emissivity coefficients for $3 \% \mathrm{w} / \mathrm{w}$ nanoparticles is the result of a proper dispersion of nanoparticles in a polyurethane matrix. The same results were observed in the SEM images of the modified nano $\mathrm{Al}_{2} \mathrm{O}_{3}$.

The dispersion in the coating is approximately the same for both particles, and the modified nanoparticles are evenly dispersed. This proper distribution is also evident in the results. However, in modified aluminum oxide nanoparticles, the aggregates of particles are higher than in zirconium oxide and larger particles are seen, which is related to the intrinsic properties of aluminum oxide and its intermolecular interactions. These gatherings are also well-distributed. As can be seen in Fig. 1, in the 5\% sample of both nanoparticles, these aggregations have increased and the properties have changed.

The results of absorption and emissivity coefficients shown that coating with modified nano $\mathrm{ZrO}_{2}$ was acted better than modified nano $\mathrm{Al}_{2} \mathrm{O}_{3}$. Regardless of the differences in the nature of the particles, the microscopic images for samples with $3 \% \mathrm{w} / \mathrm{w}$ show that particle dispersion of modified nano $\mathrm{ZrO}_{2}$ is better than modified nano $\mathrm{Al}_{2} \mathrm{O}_{3}$, as the agglomeration of modified nano $\mathrm{Al}_{2} \mathrm{O}_{3}$ can be seen clearly.

Emissivity of long wavelength. The emissivity coefficients results of the samples in the wavelengths range of 3 to $35 \mu \mathrm{m}$ with standard deviation are presented in Fig. 2. The variance analysis of the samples was 
$\mathrm{ZrO}_{2}$

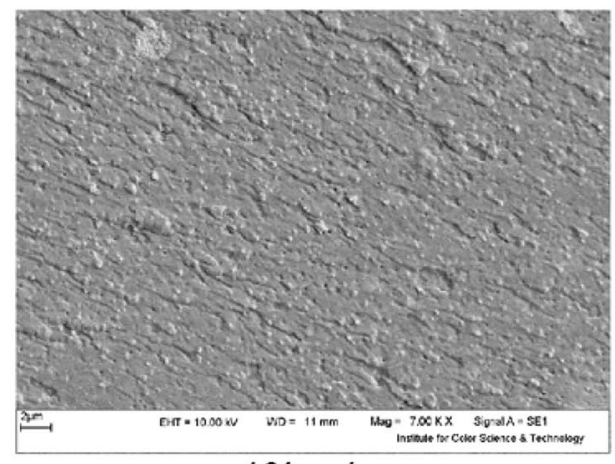

$1 \% \mathrm{w} / \mathrm{w}$

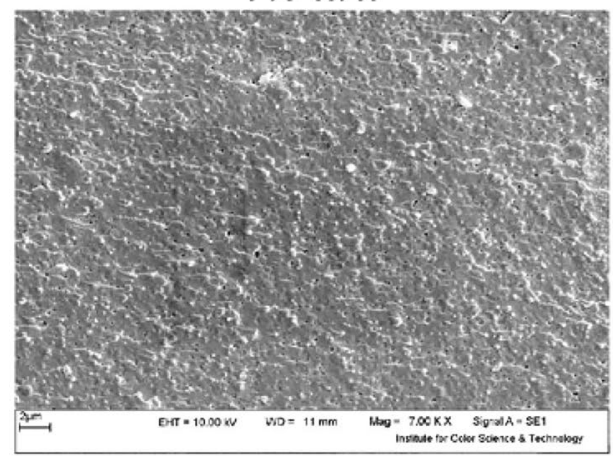

$3 \% \mathrm{w} / \mathrm{w}$

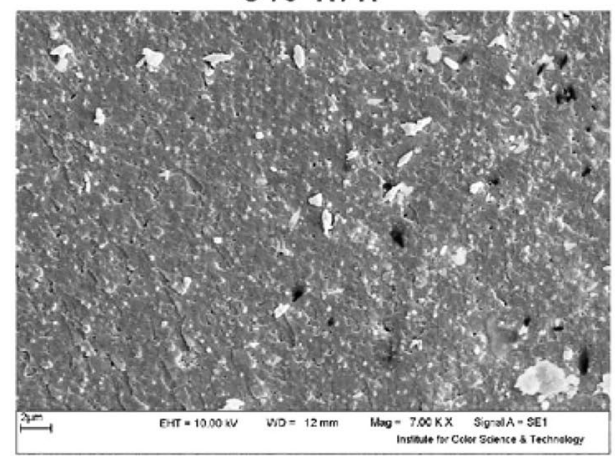

$5 \% \mathrm{w} / \mathrm{w}$
$\mathrm{Al}_{2} \mathrm{O}_{3}$

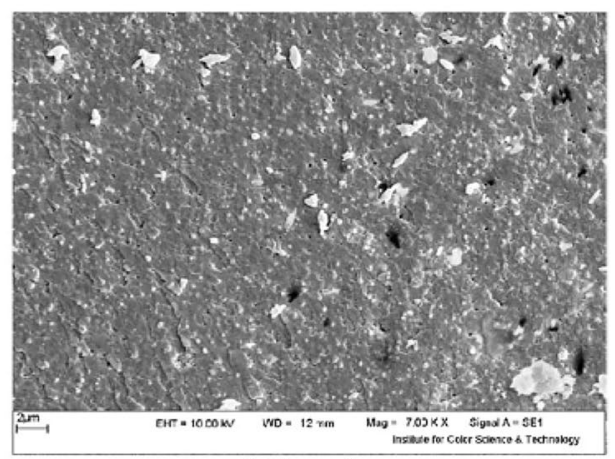

$1 \% \mathrm{w} / \mathrm{w}$

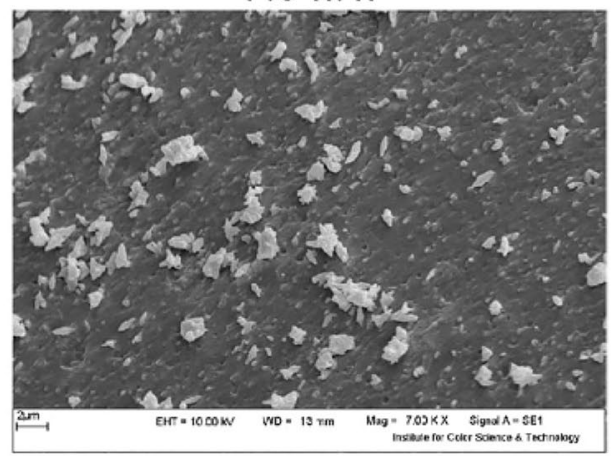

$3 \% \mathrm{w} / \mathrm{w}$

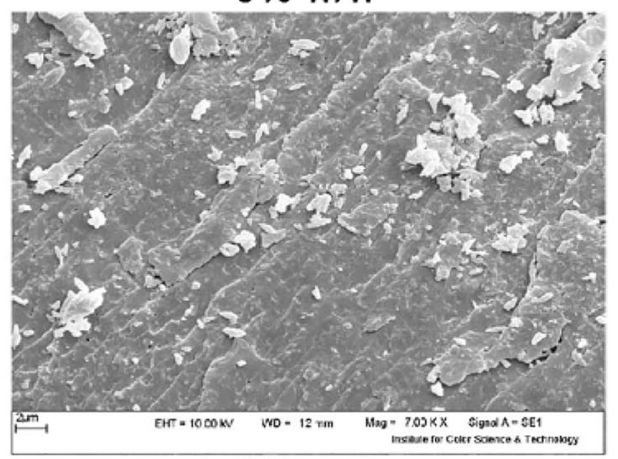

$5 \% \mathrm{w} / \mathrm{w}$

Figure 1. SEM images of polyurethane nanocomposite coatings with different amounts of nano $\mathrm{ZrO}_{2}$ and $\mathrm{Al}_{2} \mathrm{O}_{3}$.

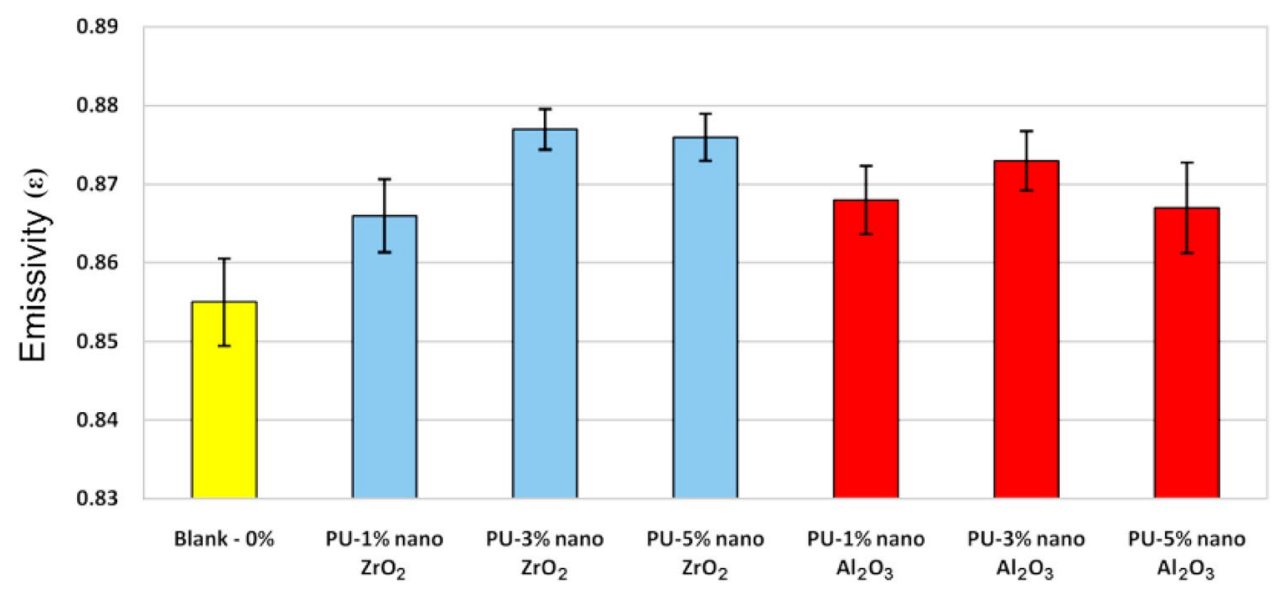

Figure 2. Emissivity coefficient with standard deviation for polyurethane nanocomposite coatings. 


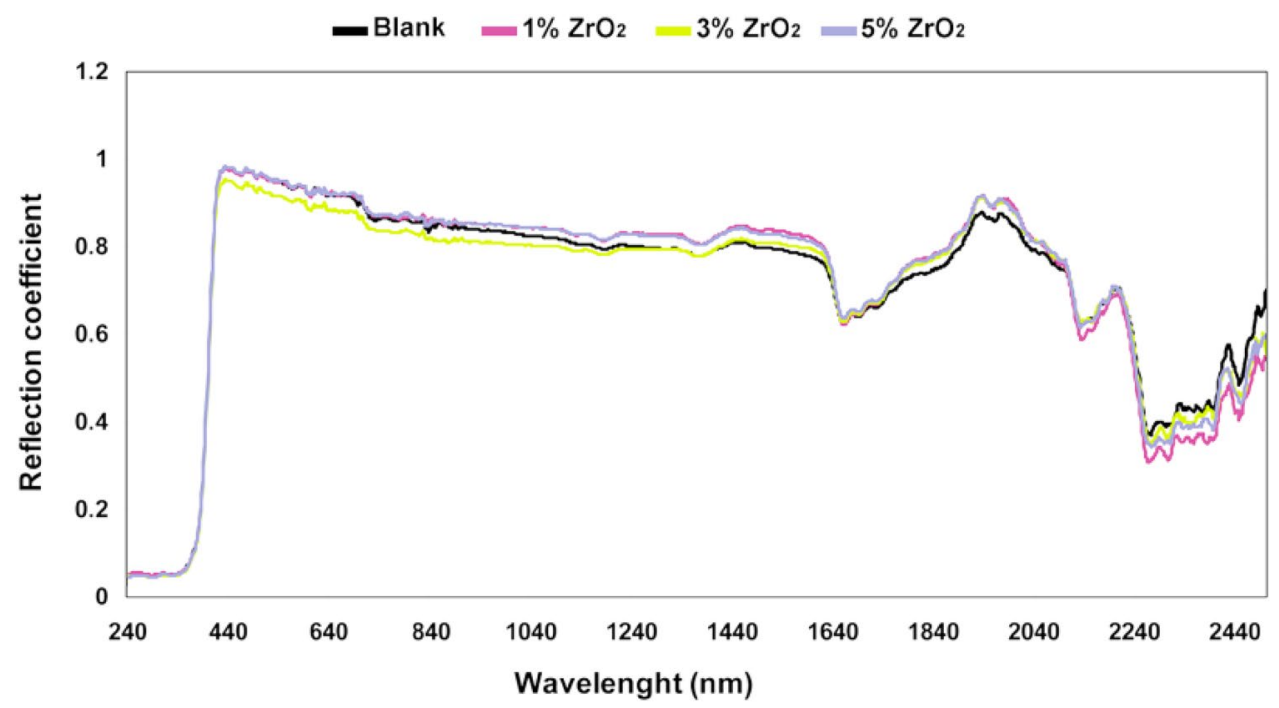

Figure 3. Absolute reflection coefficient of samples of nanocomposite coating for $0,1,3$ and $5 \%$ of zirconium oxide nanoparticles in UV/VIS/NIR region.

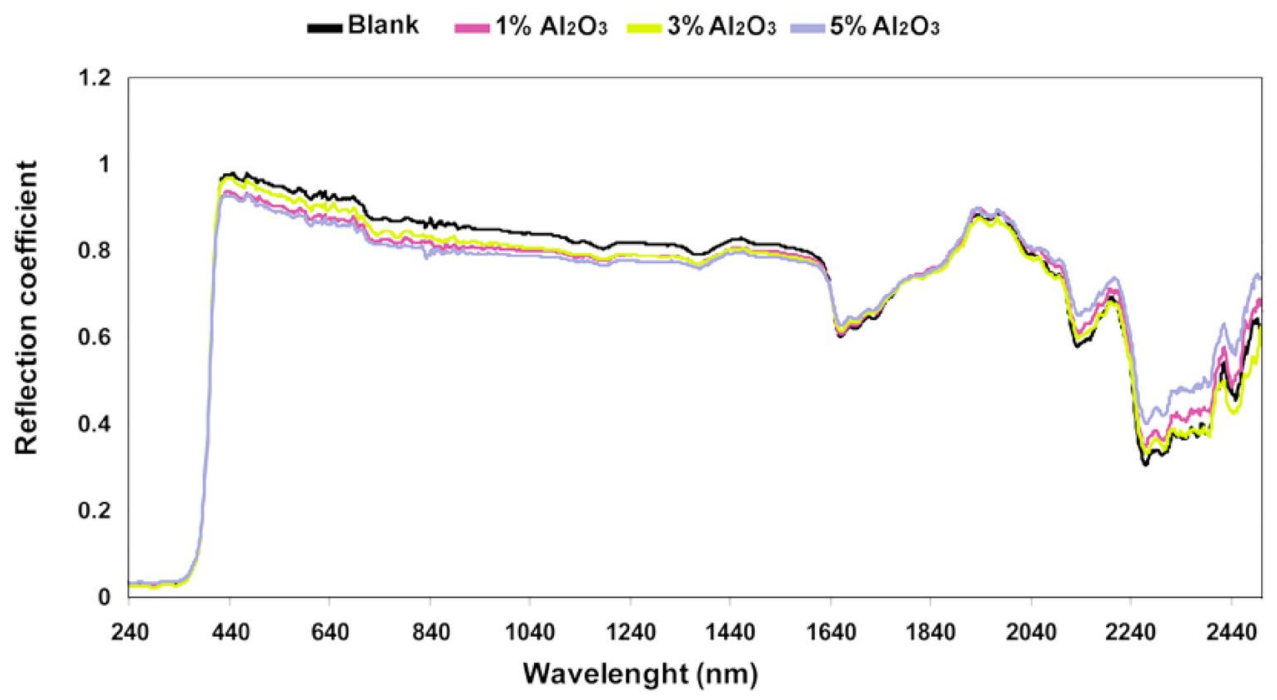

Figure 4. Absolute reflection coefficient of samples of nanocomposite coating for $0,1,3$, and $5 \%$ of aluminum oxide nanoparticles in (UV/VIS/NIR) region.

done to obtain accurate results using the data measured (minimum five times) at different parts of each sample. Results indicated that, in the wavelength of solar radiation (infrared region), the average emissivity of coatings is about 0.87 . Results showed that by adding modified nano $\mathrm{ZrO}_{2}$ and $\mathrm{Al}_{2} \mathrm{O}_{3}$ to polyurethane coatings, the emissivity coefficient of coatings compare to coating without nanoparticles increased. Also, the emissivity coefficient of coatings for the sample with $3 \% \mathrm{w} / \mathrm{w}$ nano $\mathrm{ZrO}_{2}$ compare to 1 and $5 \% \mathrm{w} / \mathrm{w}$ of nano $\mathrm{ZrO}_{2}$ and $3 \% \mathrm{w} / \mathrm{w}$ nano $\mathrm{Al}_{2} \mathrm{O}_{3}$ compare to 1 and $5 \% \mathrm{w} / \mathrm{w}$ of nano $\mathrm{Al}_{2} \mathrm{O}_{3}$ are increased. It can be concluded that these nanoparticles with the optimum amount of $3 \% \mathrm{w} / \mathrm{w}$ have a positive role in changing the emissivity coefficient and the effect of nano $\mathrm{ZrO}_{2}$ are more than nano $\mathrm{Al}_{2} \mathrm{O}_{3}$. The reason for the higher emissivity coefficient of samples with $3 \% \mathrm{w} / \mathrm{w}$ nanoparticles in comparison to the samples containing $5 \% \mathrm{w} / \mathrm{w}$ nanoparticles is due to a better dispersion of nanoparticles in the polymeric matrix. In samples containing $5 \% \mathrm{w} / \mathrm{w}$ aggregation of nanoparticles has happened.

Absorption coefficient of short wavelength. The reflection coefficients of the coated samples in region wavelengths of 0.2 to $2.5 \mu \mathrm{m}$ were measured as shown in Figs. 3 and 4 . In all cases, the reflection coefficient in the UV region (about $0.4 \mu \mathrm{m}$ ) is a bit more than expected, which is encountered due to the fluorescent effect of nano- 


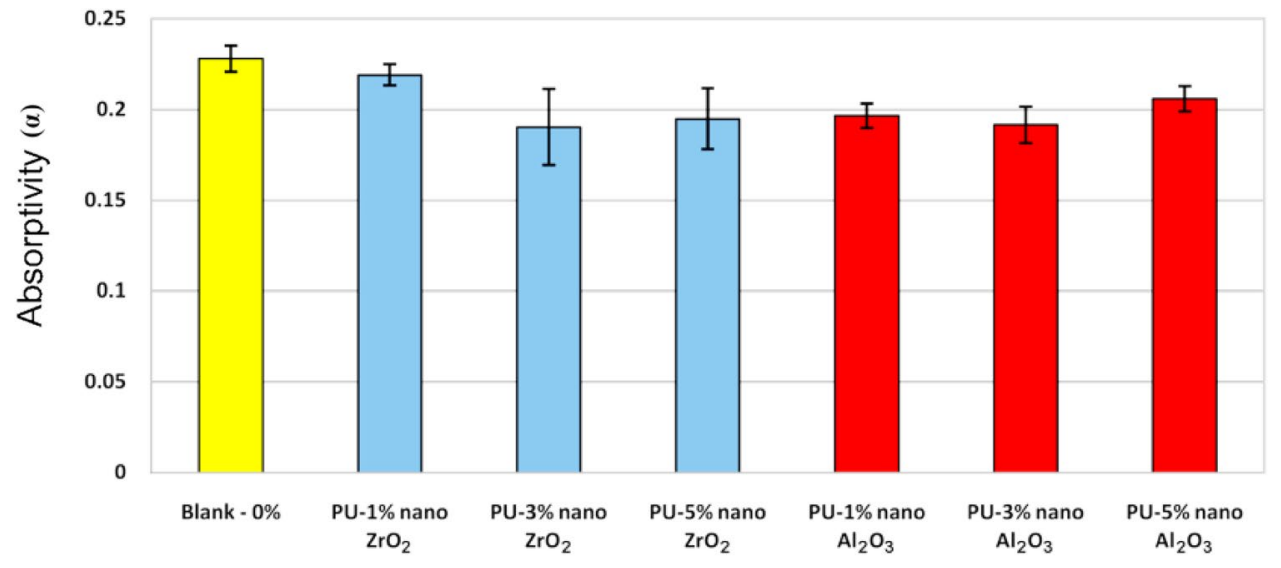

Figure 5. Absorption coefficient with standard deviation for polyurethane nanocomposite coatings.

particles in coatings, which has been reported in the literature ${ }^{37}$. Binder weight ratio effects and additives that adding to the polyurethane, change color and surface roughness that may help to increase reflection coefficient ${ }^{38}$.

Since the samples are not transmittance, the transmission coefficient is equal to zero. By integrating the results in this region, hemispherical spectral reflection coefficients were obtained, and using Eq. (1), the absorption coefficient was calculated. It is observed that in a region wavelength of UV/VIS/NIR, the absorption coefficient of the coatings is satisfied at about 0.2 . The variance analysis was done to obtain accurate results using a minimum of five data measured at different parts of each sample. Figure 5 presents a comparison of absorption coefficient results of different samples with the standard deviation.

Results indicated that by adding modified nano $\mathrm{ZrO}_{2}$ and $\mathrm{Al}_{2} \mathrm{O}_{3}$ to polyurethane coating, the absorption coefficient of the coating decreased in all samples compared to the coating without nanoparticles. It means that modified nano $\mathrm{ZrO}_{2}$ and $\mathrm{Al}_{2} \mathrm{O}_{3}$ have the ability to reduce absorption coefficient in coatings as a natural feature. It is worth mentioning that the same result is captured for the sample with $3 \% \mathrm{w} / \mathrm{w}$ nanoparticle with decreased absorption coefficient more than the other cases (the best sample for increasing the emissivity coefficient).

According to Eq. (2), it is clear that if the emissivity coefficient is high and the absorption coefficient is low, the amount of input radiation heat flux to the exterior surfaces is reduced, which, decreases the temperature of the interior surface and consequently reduces the amount of cooling load necessary to bring the space temperature to comfort temperature range.

The infrared thermography results. The temperature results of infrared thermography (IRT) of polyurethane coating with different amounts of nano $\mathrm{ZrO}_{2}$ and $\mathrm{Al}_{2} \mathrm{O}_{3}$ particles are shown in Fig. 6 . As indicated in this Figure, the temperature of points M1 to M5, average surface temperature, and the temperature points of the P line, were determined for each sample. It should be noted that the measurements of surfaces temperature were done according to the impact emissivity coefficient of the specimens.

It is worth mentioning that, in addition to the variation of the emissivity coefficient of the surfaces dependent on different weight percentages of nanoparticles, the temperature of the surfaces is changed as the result of the effect of different weight percentages of $\mathrm{ZrO}_{2}$ and $\mathrm{Al}_{2} \mathrm{O}_{3}$ nanoparticles.

The temperature at different points of the samples with nanocomposite coating having $0,1,3$, and $5 \%$ of $\mathrm{ZrO}_{2}$ and $\mathrm{Al}_{2} \mathrm{O}_{3}$ nanoparticles, is shown in Fig. 7. The result indicated that the temperature at $3 \%$ is lower than the other samples, which is due to the influence of $\mathrm{ZrO}_{2}$ and $\mathrm{Al}_{2} \mathrm{O}_{3}$ nanoparticles with polyurethane matrix, dispersion quality of nanoparticles in coatings. A slight abnormal increase in temperature in the $1 \%$ zirconium oxide sample compared to the blank sample is due to the lack of unintentional unequal conditions or error at the time of measurement. But considering the errors, it is clear that it is almost equal to the blank sample.

It is worth mentioning that, the amount of flux crossing of the surface is decreasing by reducing the temperature, which causes the reduction of heat transfer reduces and the amount of energy consumption.

\section{Conclusion}

In this study, polyurethane powder coatings nanocomposite with 1,3 , and $5 \%$ of aluminum oxide and zirconium oxide were prepared and then coated on metal plates and various tests were performed on them. Results showed that the existence of nanoparticles could have a significant effect in changing the thermal behavior of polymeric coatings. These effects depend on the nature, amount, and morphology of nanoparticles in the nanocomposite coating. Also, it is shown that by adding zirconium oxide and aluminum oxide nanoparticles to the polyurethane matrix, the emission coefficient of the coating in a region of IR was increased. The maximum emission 


\section{$\mathrm{ZrO}_{2}$}

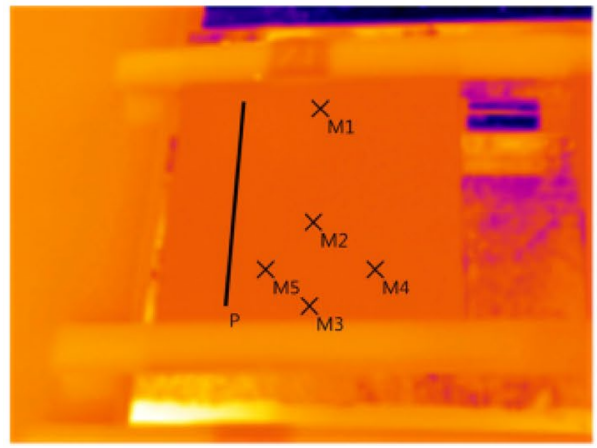

$1 \% \mathrm{w} / \mathrm{w}$

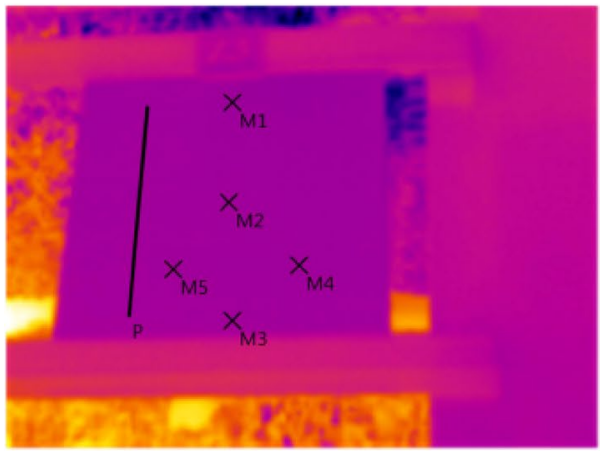

$3 \% \mathrm{w} / \mathrm{w}$

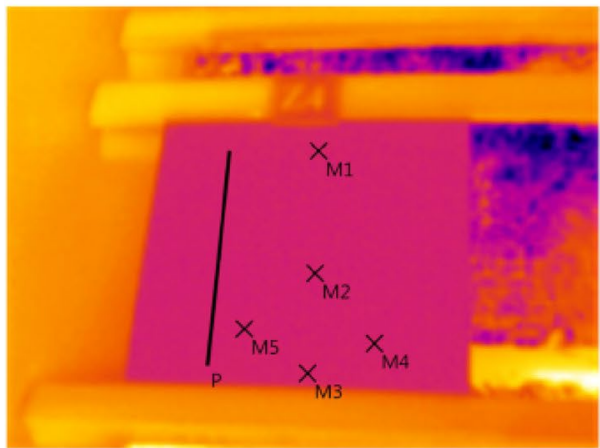

$5 \% \mathrm{w} / \mathrm{w}$
$\mathrm{Al}_{2} \mathrm{O}_{3}$
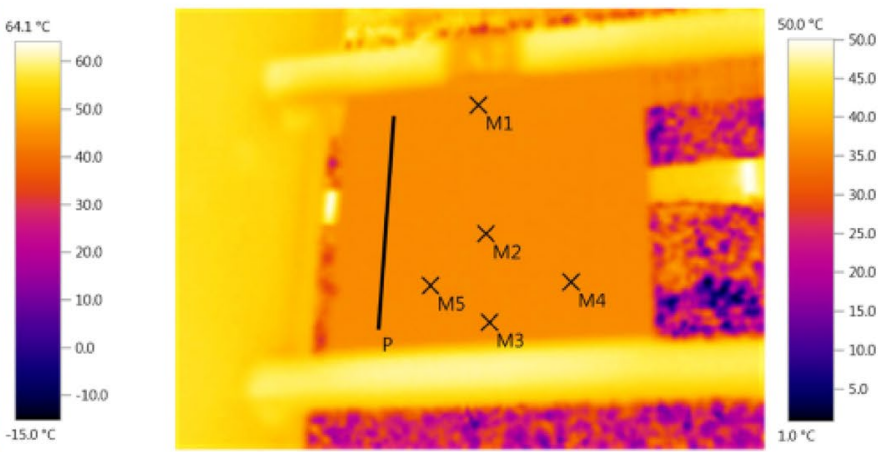

$1 \% \mathrm{w} / \mathrm{w}$

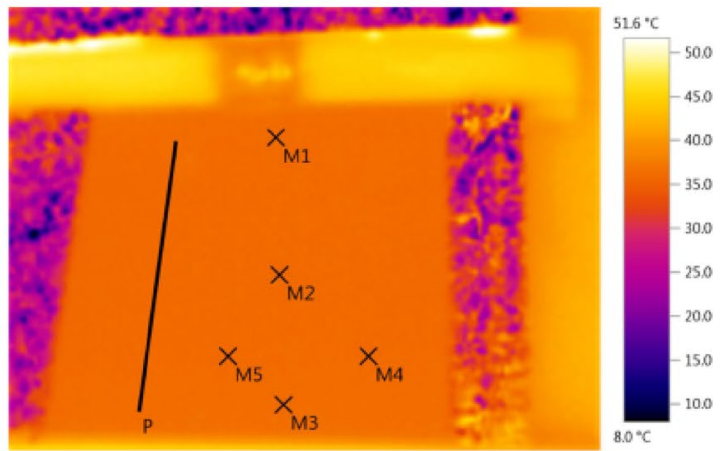

$3 \% \mathrm{w} / \mathrm{w}$

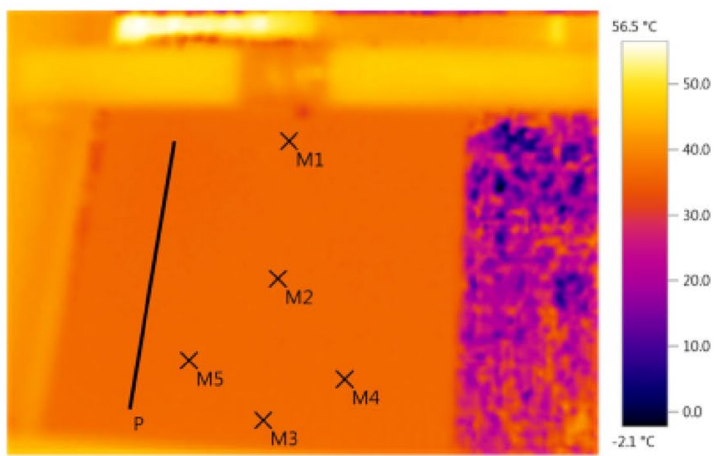

$5 \% \mathrm{w} / \mathrm{w}$

Figure 6. Thermography of images of polyurethane nanocomposite coatings with different amounts of nano $\mathrm{ZrO}_{2}$ and $\mathrm{Al}_{2} \mathrm{O}_{3}$.

coefficient was observed in $\mathrm{PU} / 3 \% \mathrm{w} / \mathrm{w}$ nano $\mathrm{ZrO}_{2}$. In addition, the absorption coefficient of the $\mathrm{PU} / \mathrm{nano}_{\mathrm{ZrO}}$ and $\mathrm{Al}_{2} \mathrm{O}_{3}$ coatings in a region of UV/VIS/NIR (all cases) compared to the blank case was decreased. The minimum absorption coefficient was measured for $\mathrm{PU} / 3 \% \mathrm{w} / \mathrm{w}$ nano $\mathrm{ZrO}_{2}$ case. The lowest surface temperature was determined for $\mathrm{PU} / 3 \% \mathrm{w} / \mathrm{w}$ nano $\mathrm{ZrO}_{2}$ sample as proven by the thermography results. 


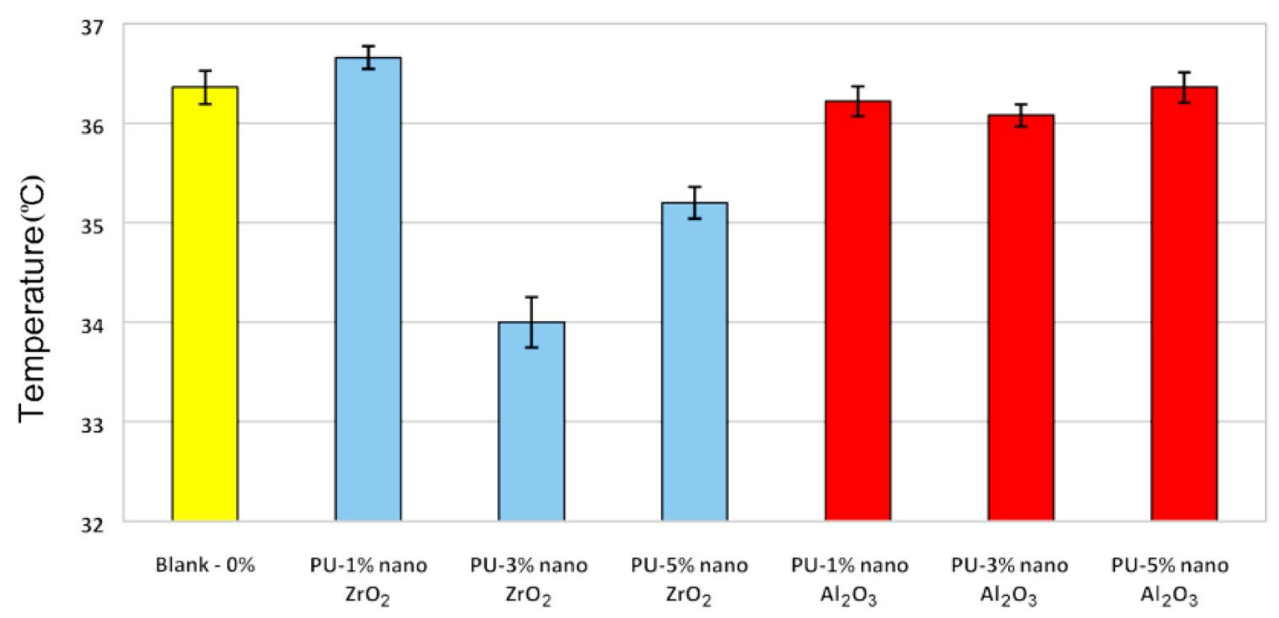

Figure 7. Temperature of the samples of polyurethane coating with $0,1,3$, and $5 \%$ of nano $\mathrm{ZrO}_{2}$ and $\mathrm{Al}_{2} \mathrm{O}_{3}$.

Received: 9 June 2021; Accepted: 6 October 2021

Published online: 19 October 2021

\section{References}

1. Horie, C. V. Materials for Conservation: Organic Consolidants, Adhesives and Coatings (Routledge, 2010).

2. Nguyen, T. D. et al. Electrochromic smart glass coating on functional nano-frameworks for effective building energy conservation. Mater. Today Energy 18, 100496 (2020).

3. Karimzadeh, A., Koloor, S. S. R., Ayatollahi, M. R., Bushroa, A. R. \& Yahya, M. Y. Assessment of nano-indentation method in mechanical characterization of heterogeneous nanocomposite materials using experimental and computational approaches. Sci. Rep. 9, 1-14 (2019).

4. Rahimian Koloor, S. S. et al. An energy-based concept for yielding of multidirectional FRP composite structures using a mesoscale lamina damage model. Polymers 12, 157 (2020).

5. Synnefa, A., Santamouris, M. \& Livada, I. A study of the thermal performance of reflective coatings for the urban environment. Sol. Energy 80, 968-981 (2006).

6. Shen, H., Tan, H. \& Tzempelikos, A. The effect of reflective coatings on building surface temperatures, indoor environment and energy consumption-An experimental study. Energy Build. 43, 573-580 (2011).

7. Sheikhzadeh, G., Azemati, A., Khorasanizadeh, H., Hadavand, B. S. \& Saraei, A. The effect of mineral micro particle in coating on energy consumption reduction and thermal comfort in a room with a radiation cooling panel in different climates. Energy Build. 82, 644-650 (2014).

8. Azemati, A. A., Hadavand, B. S., Hosseini, H. \& Tajarrod, A. S. Thermal modeling of mineral insulator in paints for energy saving. Energy Build. 56, 109-114 (2013).

9. Wijewardane, S. \& Goswami, D. A review on surface control of thermal radiation by paints and coatings for new energy applications. Renew. Sustain. Energy Rev. 16, 1863-1873 (2012).

10. Rosenfeld, A. H., Akbari, H., Romm, J. J. \& Pomerantz, M. Cool communities: Strategies for heat island mitigation and smog reduction. Energy Build. 28, 51-62 (1998).

11. Synnefa, A., Santamouris, M. \& Akbari, H. Estimating the effect of using cool coatings on energy loads and thermal comfort in residential buildings in various climatic conditions. Energy Build. 39, 1167-1174 (2007).

12. Mohammadi, K. \& Khorasanizadeh, H. A review of solar radiation on vertically mounted solar surfaces and proper azimuth angles in six Iranian major cities. Renew. Sustain. Energy Rev. 47, 504-518 (2015).

13. Emiliani, M. Development of measurement procedures for the evaluation of energy performances and ageing resistance of innovative cool coloured materials. (2014).

14. Joudi, M. A. Radiation Properties of Coil-Coated Steel in Building Envelope Surfaces and the Influence on Building Thermal Performance (Linköping University Electronic Press, 2015).

15. Ascione, F., Bianco, N., De Masi, R. F., Mauro, G. M. \& Vanoli, G. P. Design of the building envelope: A novel multi-objective approach for the optimization of energy performance and thermal comfort. Sustainability 7, 10809-10836 (2015).

16. Moaref, M., Zolfaghari, S. \& Omidvar, A. Proper design of the facade and theouter shell of the building is an effective way to prevent the occurrence of condensation in the cooling system, radiant ceiling. Iran. J. Energy 10, 3-18 (2006).

17. Jeevanandam, P. et al. Near infrared reflectance properties of metal oxide nanoparticles. J. Phys. Chem. C 111, 1912-1918 (2007).

18. Murphy, A. Modified Kubelka-Munk model for calculation of the reflectance of coatings with optically-rough surfaces. J. Phys. D Appl. Phys. 39, 3571 (2006).

19. Liu, F., Yang, L. \& Han, E. Effect of particle sizes and pigment volume concentrations on the barrier properties of polyurethane coatings. J. Coat. Technol. Res. 7, 301-313 (2010).

20. Madhi, A., Shirkavand Hadavand, B. \& Amoozadeh, A. Thermal conductivity and viscoelastic properties of UV-curable urethane acrylate reinforced with modified $\mathrm{Al}_{2} \mathrm{O}_{3}$ nanoparticles. Prog. Color Color. Coat. 10, 193-204 (2017).

21. Madhi, A., Shirkavand Hadavand, B. \& Amoozadeh, A. UV-curable urethane acrylate zirconium oxide nanocomposites: Synthesis, study on viscoelastic properties and thermal behavior. J. Composite Mater. 52, 2973-2982 (2018).

22. Tikhani, F. et al. Polyurethane/silane-functionalized $\mathrm{ZrO}_{2}$ nanocomposite powder coatings: Thermal degradation kinetics. Coatings 10, $413(2020)$.

23. Hadavand, B. S. et al. Silane-functionalized $\mathrm{Al}_{2} \mathrm{O}_{3}$-modified polyurethane powder coatings: Nonisothermal degradation kinetics and mechanistic insights. J. Appl. Polym. Sci. 137, 49412 (2020).

24. Jouyandeh, M. et al. Thermal-resistant polyurethane/nanoclay powder coatings: Degradation kinetics study. Coatings 10, 871 (2020). 
25. Verma, J., Nigam, S., Sinha, S. \& Bhattacharya, A. Development of polyurethane based anti-scratch and anti-algal coating formulation with silica-titania core-shell nanoparticles. Vacuum 153, 24-34. https://doi.org/10.1016/j.vacuum.2018.03.034 (2018).

26. Verma, J., Baghel, V., Sikarwar, B. S., Bhattacharya, A. \& Avasthi, D. Advances in Industrial and Production Engineering 117-126 (Springer, 2019).

27. Verma, J., Khanna, A. S., Sahney, R. \& Bhattacharya, A. Super protective anti-bacterial coating development with silica-titania nano core-shells. Nanoscale Adv. 2, 4093-4105. https://doi.org/10.1039/D0NA00387E (2020).

28. Hadavand, B. S., Ataeefard, M. \& Bafghi, H. F. Preparation of modified nano ZnO/polyester/TGIC powder coating nanocomposite and evaluation of its antibacterial activity. Compos. B Eng. 82, 190-195 (2015).

29. Zhai, L., Lu, D., Fan, N., Wang, X. \& Guan, R. Facile fabrication and modification of polyacrylate/silica nanocomposite latexes prepared by silica sol and silane coupling agent. J. Coat. Technol. Res. 10, 799-810 (2013).

30. ASTM, E. 408. Standard test methods for total normal emittance of surfaces using inspection-meter techniques. Annual Book of ASTM Standards, Vol. 15.

31. Robitaille, P.-M. On the validity of Kirchhoff's law of thermal emission. IEEE Trans. Plasma Sci. 31, 1263-1267 (2003).

32. Duffie, J. A. \& Beckman, W. A. Solar Engineering of Thermal Processes (Wiley, 2013).

33. Siegel, R. Thermal Radiation Heat Transfer (CRC Press, 2001).

34. ASTM, E. Standard Test Method for Solar Absorptance, Reflectance, and Transmittance of Materials using Integrating Spheres (2012).

35. Ng, T. P., Koloor, S. S., Djuansjah, J. R. \& Kadir, M. A. Assessment of compressive failure process of cortical bone materials using damage-based model. J. Mech. Behav. Biomed. Mater. 66, 1-11. https://doi.org/10.1016/j.jmbbm.2016.10.014 (2017).

36. Abdi, B., Koloor, S., Abdullah, M., Amran, A. \& Yahya, M. Y. Applied Mechanics and Materials 766-770 (Trans Tech Publ).

37. Izawa, M., Applin, D., Norman, L. \& Cloutis, E. Reflectance spectroscopy (350-2500 nm) of solid-state polycyclic aromatic hydrocarbons (PAHs). Icarus 237, 159-181 (2014)

38. Fang, V., Kennedy, J. V., Futter, J. \& Manning, J. A Review of Near Infrared Reflectance Properties of Metal Oxide Nanostructures (GNS Science, 2013)

\section{Acknowledgements}

The research was supported by the Ministry of Education, Youth, and Sports of the Czech Republic and the European Union (European Structural and Investment Funds Operational Program Research, Development, and Education) in the framework of the project "Modular platform for autonomous chassis of specialized electric vehicles for freight and equipment transportation”, Reg. No. CZ.02.1.01/0.0/0.0/16_025/0007293.

\section{Author contributions}

Conceptualization, methodology, validation, formal analysis, and investigations were done by A.A.A., S.S.R.K., H.K., M.P., G.A.S., M.S., and B.S.H.; Resources, funding acquisition, supervision and project administration: A.A.A., S.S.R.K., M.P., and B.S.H.; Data curation, writing-original draft preparation, writing-review and editing were done by A.A.A., S.S.R.K., and B.S.H. All authors have read and agreed to the published version of the manuscript.

\section{Competing interests}

The authors declare no competing interests.

\section{Additional information}

Correspondence and requests for materials should be addressed to S.S.R.K. or B.S.H.

Reprints and permissions information is available at www.nature.com/reprints.

Publisher's note Springer Nature remains neutral with regard to jurisdictional claims in published maps and institutional affiliations.

(c) (i) Open Access This article is licensed under a Creative Commons Attribution 4.0 International License, which permits use, sharing, adaptation, distribution and reproduction in any medium or format, as long as you give appropriate credit to the original author(s) and the source, provide a link to the Creative Commons licence, and indicate if changes were made. The images or other third party material in this article are included in the article's Creative Commons licence, unless indicated otherwise in a credit line to the material. If material is not included in the article's Creative Commons licence and your intended use is not permitted by statutory regulation or exceeds the permitted use, you will need to obtain permission directly from the copyright holder. To view a copy of this licence, visit http://creativecommons.org/licenses/by/4.0/.

(C) The Author(s) 2021 